\title{
Interaction of Graphene Oxide Modified with Linear and Branched PEG with Monocytes Isolated from Human Blood
}

\author{
Pavel Khramtsov ${ }^{1, *}{ }^{1}$, Maria Bochkova ${ }^{1}$, Valeria Timganova ${ }^{1} \mathbb{D}$, Anton Nechaev ${ }^{2}$, Sofya Uzhviyuk ${ }^{1}$, \\ Kseniya Shardina ${ }^{1}{ }^{10}$, Irina Maslennikova ${ }^{1}$, Mikhail Rayev ${ }^{1}$ and Svetlana Zamorina ${ }^{1}$ \\ 1 Institute of Ecology and Genetics of Microorganisms UB RAS, 13 Golev str., 614081 Perm, Russia; \\ krasnykh-m@mail.ru (M.B.); timganovavp@gmail.com (V.T.); kochurova.sofja@yandex.ru (S.U.); \\ shardinak@gmail.com (K.S.); i.maslennikova1974@gmail.com (I.M.); mraev@iegm.ru (M.R.); \\ mantissa7@mail.ru (S.Z.) \\ 2 Institute of Technical Chemistry UB RAS, 3 Academician Korolev str., 614013 Perm, Russia; \\ nechaev.a@itcras.ru \\ * Correspondence: khramtsovpavel@yandex.ru; Tel.: +7-342-280-77-94
}

\section{check for}

updates

Citation: Khramtsov, P.; Bochkova,

M.; Timganova, V.; Nechaev, A.;

Uzhviyuk, S.; Shardina, K.;

Maslennikova, I.; Rayev, M.;

Zamorina, S. Interaction of Graphene

Oxide Modified with Linear and

Branched PEG with Monocytes

Isolated from Human Blood.

Nanomaterials 2022, 12, 126. https://

doi.org/10.3390/nano12010126

Academic Editor: Jin Suk Chung

Received: 28 November 2021

Accepted: 24 December 2021

Published: 30 December 2021

Publisher's Note: MDPI stays neutral with regard to jurisdictional claims in published maps and institutional affiliations.

Copyright: (c) 2021 by the authors. Licensee MDPI, Basel, Switzerland. This article is an open access article distributed under the terms and conditions of the Creative Commons Attribution (CC BY) license (https:// creativecommons.org/licenses/by/ $4.0 /)$.

\begin{abstract}
Multiple graphene-based therapeutics have recently been developed, however potential risks related to the interaction between nanomaterials and immune cells are still poorly understood. Therefore, studying the impact of graphene oxide on various populations of immune cells is of importance. In this work, we aimed to investigate the effects of PEGylated graphene oxide on monocytes isolated from human peripheral blood. Graphene oxide nanoparticles with lateral sizes of 100-200 nm and 1-5 $\mu \mathrm{m}$ were modified with linear and branched PEG (GO-PEG). Size, elemental composition, and structure of the resulting nanoparticles were characterized. We confirmed that PEG was successfully attached to the graphene oxide surface. The influence of GO-PEG on the production of reactive oxygen species (ROS), cytokines, phagocytosis, and viability of monocytes was studied. Uptake of GO-PEG by monocytes depends on PEG structure (linear or branched). Branched PEG decreased the number of GO-PEG nanoparticles per monocyte. The viability of monocytes was not altered by co-cultivation with GO-PEG. GO-PEG decreased the phagocytosis of Escherichia coli in a concentration-dependent manner. ROS formation by monocytes was determined by measuring luminol-, lucigenin-, and dichlorodihydrofluorescein-dependent luminescence. GO-PEG decreased luminescent signal probably due to inactivation of ROS, such as hydroxyl and superoxide radicals. Some types of GO-PEG stimulated secretion of IL-10 by monocytes, but this effect did not correlate with their size or PEG structure.
\end{abstract}

Keywords: graphene oxide; immune cells; monocytes; viability; polyethylene glycol

\section{Introduction}

Graphene is a 2D carbon allotrope consisting of $\mathrm{sp}^{2}$ hybridized carbon atoms arranged in a honeycomb-like hexagonal lattice. Possessing a plethora of properties that are highly desirable for biomedical applications, graphene and its derivatives have attracted an enormous amount of attention from researchers [1]. Graphene oxide (GO) is an oxidized form of graphene containing carboxyl, hydroxyl, carbonyl, and epoxy groups on the edges of the lattice [2]. Polar functional groups endow graphene oxide with colloidal stability in water and provide sites for covalent functionalization.

Given the development of nanomedicine, it has become especially urgent to study the effects of nanomaterials in general and nanoparticles in particular on the function of cells of the immune system [3]. Graphene oxide can act as a scavenger of reactive oxygen species (ROS) [4] and has been applied to manipulate ROS-dependent polarization of macrophage cells in the site of inflammation [5]. Due to the ability of GO to change immune response polarization, cytokine production, and secretion of antibodies, it is broadly considered as a component of adjuvants [6,7] and immunotherapeutics [8]. 
Application of GO in vivo often requires its parenteral administration, which inevitably leads to interaction with immune cells in the bloodstream or the tissue fluid. Many recent studies shed some light on alteration of an immune response upon GO administration, however, effects of GO on some classes of immune cells, such as monocytes, dendritic cells, NK-cells, and so on, are still poorly understood [7,9]. In this regard, our study aims at the assessment of the viability and function of monocytes upon interaction with GO.

Monocytes, together with neutrophils, are important cells of innate immunity that protect the body from pathogenic microbes. The main functions of monocytes are phagocytosis, antigen presentation, and immunomodulation $[10,11]$. Being professional phagocytes, monocytes play a significant role in the removal of dead cells and cellular debris as well as in pathogen elimination [12,13]. Monocytes and monocyte-derived macrophages are actively involved in pathological processes in diseases such as cancer, atherosclerosis, arthritis, and inflammatory lung diseases [14]. Research is currently underway to target nanoparticles to these cells to diagnose and treat the above diseases [14].

Size [15] and coating [16] of GO both impact its uptake and alteration of cell physiology. Pristine GO has little potential to be utilized in clinics, because of its poor colloidal stability in saline and high cytotoxicity [17]. Modification with various polymers can significantly improve both stability and biocompatibility of GO. Polyethylene glycol (PEG) is a biocompatible polymer and a component of multiple nanoformulations approved for both clinical application and for undergoing clinical trials [18]. Indeed, recent studies have reported improved biocompatibility of PEG-modified GO in comparison with unmodified counterparts [17]. Given the above information, in this work, we examined GO nanoparticles whose lateral size differed by almost one order of magnitude: 100-200 nm and 1-5 $\mu \mathrm{m}$. GO was modified with linear and eight-armed branched PEG. We grafted these two types of PEG polymer to GO based on results obtained by Xu et al. [19] who demonstrated that branched PEG provides better colloidal stability to GO nanoparticles in comparison with linear PEG. Experiments were performed with monocytes isolated from human peripheral blood using magnetic beads conjugated with anti-CD14 antibodies.

The aim of the study was to assess the effect of PEGylated GO on the functions of monocytes that are relevant for pathogen elimination and polarization of immune response.

The goals of the current study included:

1. Synthesis and characterization of PEG-modified GO nanoparticles

2. Assessment of protein adsorption on PEG-modified GO nanoparticles

3. Studying the effects of PEGylated GO on the viability of monocytes, nanoparticle uptake, cytokine production, phagocytosis, and ROS formation.

\section{Materials and Methods}

\subsection{Materials and Instrumentation}

Graphene oxide powder (lateral size of 100-200 $\mathrm{nm}$ and 1-5 $\mu \mathrm{m}$ ) was obtained from Ossila Ltd. (Sheffield, UK). Monochloroacetic acid, 1-(3-dimethylaminopropyl)-3ethylcarbodiimide hydrochloride (EDC), N-hydroxysuccinimide (NHS), 8-arm-PEG- $\mathrm{NH}_{2}$ $(10,000 \mathrm{kDa})$, methoxy polyethylene glycol amine $(5 \mathrm{kDa})$ were obtained from Alfa Aesar (Ward Hill, MA, USA). Dichlorodihydrofluorescein diacetate (DCFH), polymyxin B, bovine serum albumin (BSA), lipopolysaccharide (LPS) were obtained from Sigma-Aldrich (Burlington, MA, USA). RPMI-1640 culture media were obtained from Biolot (St Petersburg, Russia). Ficoll-verografin was obtained from Dia-M (Moscow, Russia). Anti-CD14 MACS ${ }^{\circledR}$ MicroBeads and MS Columns were obtained from Miltenyi Biotec (Bergisch Gladbach, Germany). ELISA kits were from Vektor-Best (Novosibirsk, Russia).

Solutions were prepared with deionized water. All reagents were used without additional purification.

Instrumentation. IFS 66/S IR spectrometer and Raman microscope SENTERRA were obtained from Bruker Corporation (Billerica, MA, USA). UV 2600 two-beam spectrophotometer was obtained from Shimadzu (Kyoto, Japan). ZetaPALS was obtained from Brookhaven Instruments Corporation (Wakefield, MA, USA). TGA/DSC 1 combined with 
TG-DSC device was obtained from Mettler-Toledo (Greifensee, Switzerland). CytoFlex S flow cytometer was obtained from Beckman Coulter (Brea, CA, USA).

\subsection{PEGylation of $G O$}

Carbodiimide-mediated coupling of PEG- $\mathrm{NH}_{2}$ and $\mathrm{GO}$ was made as follows. Aqueous solutions of $\mathrm{GO}(2 \mathrm{mg} / \mathrm{mL})$ were sonicated for $30 \mathrm{~min}$ using probe sonicator (output power was $25 \mathrm{~W}$ for small GO and $150 \mathrm{~W}$ for large GO), and then carboxylated by the addition of $\mathrm{Cl}-\mathrm{CH} 2-\mathrm{COOH}(18.5 \mathrm{mM})$ under sonication for $60 \mathrm{~min}$. Carboxylated GO nanoparticles were washed by centrifugation at 10,000 $\mathrm{g}$ with water until neutral $\mathrm{pH}$ level was reached. EDC (to $4 \mathrm{mM}$ ), NHS (to $10 \mathrm{mM}$ ), and branched or linear PEG (to $2 \mathrm{mg} / \mathrm{mL}$ ) were added to the suspension of carboxylated GO (pH 5.6) over the course of 5 min with constant ultrasonic treatment. The suspension was kept for $24 \mathrm{~h}$ at room temperature, GO-PEG was purified by dialysis, washed three times with ethanol by centrifugation $(10,000 \mathrm{~g})$, and dried under vacuum at $+65^{\circ} \mathrm{C}$.

Large $(1-5 \mu \mathrm{m}) \mathrm{GO}$ coated with linear and branched PEG will be further referred to as LnGO and LbGO, respectively. Small (100-200 nm) GO coated with linear and branched PEG will be further referred to as SnGO and SbGO, respectively. Designation "GO-PEG" will be used as a generic term for any type of PEGylated graphene oxide.

\subsection{Characterization of GO and GO-PEG}

FTIR spectra of the intact and PEGylated GO were obtained in the range $400-4000 \mathrm{~cm}^{-1}$ using $\mathrm{KBr}$ tablets ( $2 \mathrm{mg}$ of nanoparticles per $299 \mathrm{mg}$ of $\mathrm{KBr}$ ). UV-Vis spectra of GO-PEG were recorded in the range of $200-900 \mathrm{~nm}$. Hydrodynamic diameter and zeta potential were measured by dynamic light scattering (DLS). The percentage of the attached polymer was quantified by thermogravimetric analysis (TGA) at a heating rate of $10 \mathrm{~K} \mathrm{~min}^{-1}$ from 30 to $900{ }^{\circ} \mathrm{C}$ in an inert atmosphere. Raman spectra (D and $\mathrm{G}$ bands intensities) were obtained in the range $500-2000 \mathrm{~cm}^{-1}$ (laser power: $0.2 \mathrm{~mW}$; wavelength: $532 \mathrm{~nm}$ ). Scanning electron microscopy (SEM) images were obtained under an acceleration voltage of $20 \mathrm{kV}$.

\subsection{Isolation of Monocytes from Human Blood}

Venous blood was collected from the donors (healthy subjects, $n=7,25-35$ years old) by venipuncture with vacuum tubes. Written informed consent was obtained from all subjects who participated in the study. Peripheral blood mononuclear cells (PBMCs) were isolated from the venous blood by ficoll-verografin $(1.077 \mathrm{~g} / \mathrm{L})$ gradient centrifugation. Heparinized blood was 1:1 mixed with RPMI-1640, and then $6 \mathrm{~mL}$ of the resulting mixture were layered upon $3 \mathrm{~mL}$ ficoll-verografin solution. After centrifugation for $40 \mathrm{~min}$ at $400 \mathrm{~g}$ $\left(+25^{\circ} \mathrm{C}\right)$ PBMC located above the ficoll-verografin layer were collected, diluted 5-10 times with RPMI-1640, and washed three times with RPMI-1640 $(2 \times$ at $350 \mathrm{~g}$ for $20 \mathrm{~min}$ and $1 \times$ at $200 \mathrm{~g}$ for $20 \mathrm{~min}$ ). The cell pellet was diluted in $1 \mathrm{~mL}$ of RPMI-1640. The concentration of PBMC was measured using a Neubauer chamber.

Monocytes (CD14-positive cells) were purified from PBMC fraction by positive immunomagnetic separation using magnetic microbeads carrying anti-CD14 antibodies according to the manufacturer's instruction. Isolated monocytes were diluted to the required concentrations in Hanks' balanced salt solution (HBSS).

\subsection{Protein Adsorption Study}

GO-PEG $(100 \mu \mathrm{g})$ were dispersed in RPMI-1640 with $10 \%$ pooled human serum, or $10 \%$ fetal calf serum, or $0.7 \%$ BSA, which is equivalent to the total protein concentration in $10 \%$ human serum. The resulting concentration of GO-PEG was 5 and $25 \mu \mathrm{g} / \mathrm{mL}$, therefore the volume of nanoparticle suspension was 20 and $4 \mathrm{~mL}$ respectively. Nanoparticles were kept at $+37^{\circ} \mathrm{C}$ for $60 \mathrm{~min}$ on the rotator, then washed by centrifugation $(10,000 \mathrm{~g}$, $30 \mathrm{~min}$, three times) with phosphate buffer, re-dispersed in $20 \mu \mathrm{L}$ of phosphate buffer, heated at $+95^{\circ} \mathrm{C}$ for $5 \mathrm{~min}$, and analyzed by gel-electrophoresis in $10 \%$ polyacrylamide gel (SDS-PAGE). Gels were prepared using $0.1 \mathrm{M}$ TRIS-HCl buffer, $\mathrm{pH} 8.8$ with $0.1 \%$ 
SDS. Electrode buffer was TRIS-glycine buffer, $\mathrm{pH} \sim 8.4$. Concentrating gel was not used. Electrophoresis was performed at a constant voltage of $200 \mathrm{~V}$. Gels were stained with Coomassie G-250 diluted in a fixing solution (20\% methanol, $7.5 \%$ acetic acid) and destained in a fixing solution. Destained gels were photographed using a smartphone. Photographs were cropped and presented without any color manipulation. Amount of protein in each sample was semiquantitatively measured with the aid of Image J software. For this, "Analyze > Measure" tool was used, which allows measurement of the mean grey value parameter, which characterizes mean brightness of each lane (Figure S1). The more protein the lower brightness. Mean grey value is expressed in arbitrary units and varies from 0 (minimal brightness) to 255 (maximal brightness). Detailed information can be found at https: / /imagej.nih.gov/ij/ (accessed on 28 November 2021).

\subsection{Uptake of GO-PEG by Monocytes}

Monocytes were diluted in $10 \%$ pooled human serum in RPMI-1640 to $2 \times 10^{6}$ cells $/ \mathrm{mL}$. Fifty microliters of the cell suspension were combined with an equal volume of GO-PEG (resulting concentration of GO-PEG was 5 or $25 \mu \mathrm{g} / \mathrm{mL}$ ). Samples were incubated at +4 or at $+37^{\circ} \mathrm{C}$ for $30 \mathrm{~min}$ and then on ice for $5 \mathrm{~min}$. Cells were washed ( $350 \mathrm{~g}, 7 \mathrm{~min}$ ) with a cold phosphate buffer and kept on ice until analysis by flow cytometry. The uptake of GO-PEG was assessed by measuring fluorescence in the PE-Cy7 channel ( $\lambda \mathrm{ex}=488 \mathrm{~nm}$; bandpass filter: 720-840 nm). The percentage of GO-PEG-positive cells in the monocyte gate was determined (Figure 1). The phagocytosis index was determined by dividing the geometric mean of the fluorescence of the cells in the Cy7-positive gate (a linear gate placed to the right of the peak of cells in the sample without GO-PEG) by the number of cells in this gate.
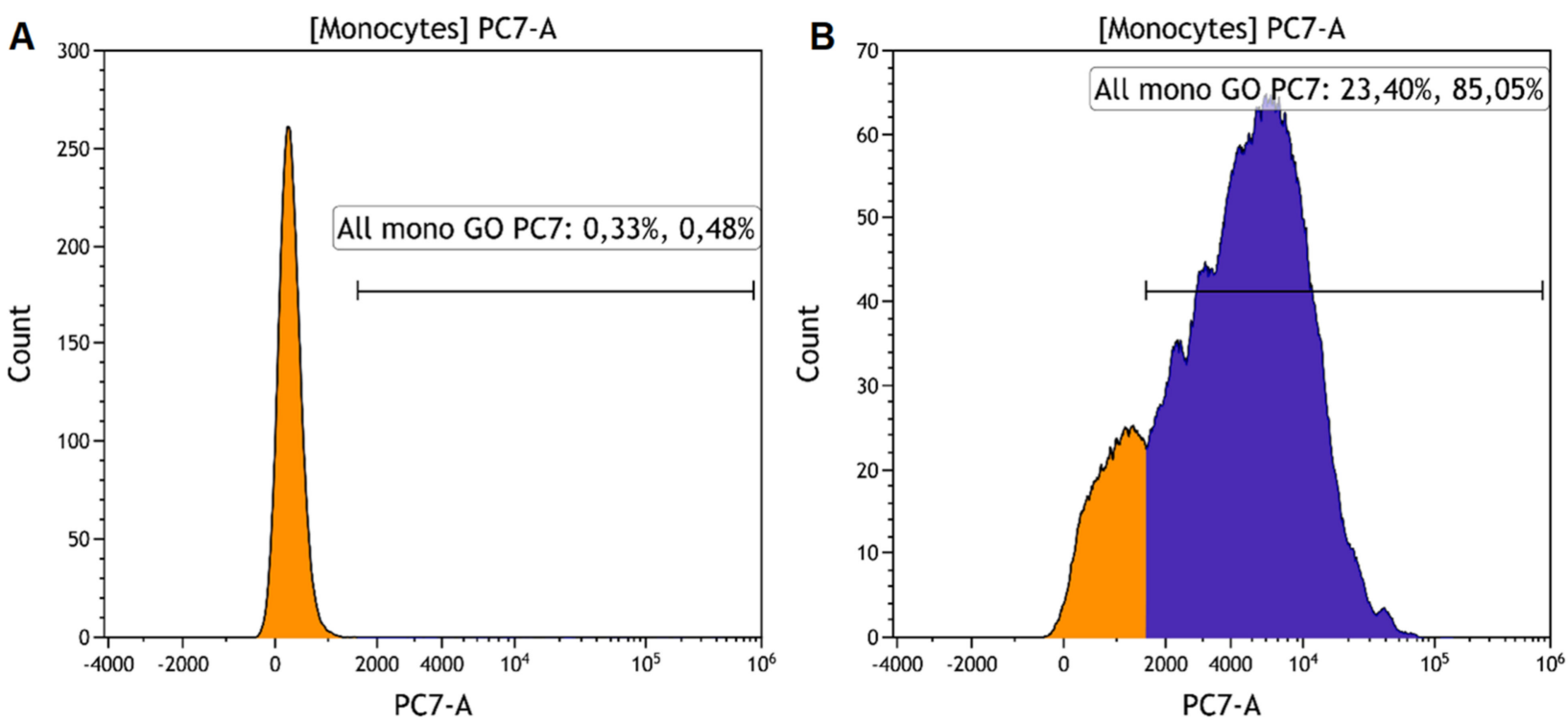

Figure 1. Histograms of cell fluorescence in PC-7 channel. (A)-control (cells without GO); (B)-sample with $25 \mu \mathrm{g} / \mathrm{mL}$ GO-PEG 1-5 $\mu \mathrm{m}$. Note: Cells entering the gate of fluorescent (PC7-positive) cells that absorbed/engulfed GO are highlighted in blue in the histogram.

\subsection{Cell Viability}

Monocytes were incubated with GO-PEG for $24 \mathrm{~h}$; then they were washed and mixed 1:1 with $0.4 \%$ Trypan Blue. The percentage of stained (dead) cells was measured by visual assessment using a light microscope (100 cells were counted per sample, and 2 replicates were taken). 


\subsection{Phagocytosis of Escherichia coli by Monocytes}

Monocytes $\left(2 \times 10^{6}\right.$ cells $\left./ \mathrm{mL}\right)$ in Phenol Red-free RPMI-1640 supplemented with 10\% fetal calf serum were mixed with GO-PEG ( 5 and $25 \mu \mathrm{g} / \mathrm{mL})$ and incubated for 30 min or $24 \mathrm{~h}$ in $\mathrm{CO} 2$ incubator $\left(5 \% \mathrm{CO}_{2} ;+37^{\circ} \mathrm{C}\right)$. Then, an equal volume of FITC-labelled E. coli K12 (laboratory strain; $2 \times 10^{7}$ cells $/ \mathrm{mL}$ ) was added, and the mixture was incubated for another $30 \mathrm{~min}$. After that, cells were placed on ice for $10 \mathrm{~min}$, washed once with $2 \mathrm{~mL}$ of cold buffer (phosphate buffer, pH 7.4 with $0.5 \%$ BSA and $0.1 \%$ sodium azide). The tubes were then placed on ice and analyzed on a CytoFlex $S$ flow cytometer. The percentage of FITC-positive cells in the monocyte gate was determined in each sample. The phagocytosis index was determined by dividing the geometric mean of the fluorescence of the cells in the FITC-positive gate (a linear gate placed to the right of the peak of cells in the sample without $E$. coli) by the number of cells in this gate.

\subsection{Production of Reactive Oxygen Species (ROS) by Monocytes}

Luminol and lucigenin chemiluminescence. Hanks' balanced salt solution, monocytes (to $10^{5}$ cells $/ \mathrm{mL}$ ), GO-PEG (to 5 or $25 \mu \mathrm{g} / \mathrm{mL}$ ), and pooled heat-inactivated human serum (to $10 \%$ ) were added to the wells of 96-well plate. Lucigenin or luminol was then added to $20 \mu \mathrm{M}$ and $5 \mu \mathrm{M}$, respectively. Finally, opsonized zymosan was added to $1.5 \mu \mathrm{g} / \mathrm{mL}$. Measurements of luminescence were performed for 90 (luminol) or $60 \mathrm{~min}$ (lucigenin) at $+37^{\circ} \mathrm{C}$ with 3 min intervals. Results are expressed in relative luminescence units (RLU) as the area under luminescence vs time curve (AUC) obtained by summarizing luminescence intensities at each time point.

DCFH fluorescence. Monocytes were stained with $100 \mu \mathrm{M} \mathrm{DCFH}$ for $30 \mathrm{~min}$ at $+37^{\circ} \mathrm{C}$ in a dark chamber; then, cells were washed with Hanks' balanced salt solution. Monocytes concentration was adjusted to $2 \times 10^{6}$ cells $/ \mathrm{mL}$. Fifty microliters of the cell suspension were transferred to a 96-well plate. After that, Hanks' balanced salt solution, GO-PEG (to 5 or $25 \mu \mathrm{g} / \mathrm{mL}$ ), and pooled human blood serum (to 10\%) were added. Opsonized zymosan was added to $1.5 \mu \mathrm{g} / \mathrm{mL}$. DCFH fluorescence was measured for $60 \mathrm{~min}$ at $+37^{\circ} \mathrm{C}$ with 3 min intervals. Results are expressed in relative fluorescence units (RFU) as the area under fluorescence vs time curve (AUC) obtained by summarizing luminescence intensities at each time point.

\subsection{Cytokine Production}

Monocytes $\left(100 \mu \mathrm{L}, 2 \times 10^{6}\right.$ cells $\left./ \mathrm{mL}\right)$ were added to round-bottom 96-well plates, then RPMI-1640, pooled heat-inactivated human serum (final concentration of $10 \%$ ), polymyxin B $(10 \mu \mathrm{M})$ [20], and GO-PEG (5 or $25 \mu \mathrm{L}$ ) were added. Control samples without GO-PEG or containing LPS, $100 \mathrm{ng} / \mathrm{mL}$ ) were also prepared. Cells were grown at $5 \% \mathrm{CO}_{2}$ at $+37{ }^{\circ} \mathrm{C}$ for $24 \mathrm{~h}$. Then, plates were centrifuged $\left(10 \mathrm{~min}, 400 \mathrm{~g},+25^{\circ} \mathrm{C}\right)$ on a plate rotor, culture fluid was collected, and centrifuged at $20,000 \mathrm{~g}$ for $20 \mathrm{~min}$ at $+4^{\circ} \mathrm{C}$. Supernatants were stored at $-20{ }^{\circ} \mathrm{C}$. Cytokine measurements were made by ELISA.

\subsection{Statistical Analysis}

Statistical analysis was performed in GraphPad Prism 6.0. Friedman's test or one-way repeated measurements ANOVA with appropriate post-hoc tests were used for group comparison. In ROS production experiments, two technical replicates were completed for each donor. Average values of these replicates were used in further analyses. In other experiments, there were no technical replicates.

\section{Results and Discussion}

\subsection{Synthesis and Characterization of GO-PEG}

Effects of GO nanoparticles on living systems depend on many factors including lateral size, thickness, type of coating, elemental composition, and so on [21]. GO nanoparticles with lateral sizes of 100-200 $\mathrm{nm}$ and 1-5 $\mu \mathrm{m}$ were functionalized with PEG, a polymer capable of improving colloidal stability and the toxicity profile of nanomaterials. Two types 
of PEG were used for nanoparticle coating, namely linear PEG and branched PEG (8-armed PEG), which is based on literature data suggesting that the branched form may provide better stability in cell culture fluid [19]. Besides, previous studies have demonstrated that linear PEG is more intensively uptaken by phagocytes [22,23], to which monocytes belong, indicating that the results of interaction between cells and GO coated with linear and branched PEG can also be different.

Large $(1-5 \mu \mathrm{m}) \mathrm{GO}$ coated with linear and branched PEG will be further referred to as LnGO and LbGO, respectively. Small (100-200 nm) GO coated with linear and branched PEG will be further referred to as SnGO and SbGO, respectively. Designation "GO-PEG" will be used as a generic term for any type of PEGylated graphene oxide.

Pristine GO nanoplatelets were treated with chloroacetic acid to introduce additional carboxylic groups. Then, aminated PEG was covalently attached to carboxylated GO via carbodiimide chemistry. The resulting nanoparticles were characterized by various techniques including FTIR, Raman spectroscopy, elemental analysis (EDS), TGA, SEM, and DLS (Figure 2).

\subsubsection{FTIR}

Typical intense absorption bands (a.b.) at $3400 \mathrm{~cm}^{-1}(-\mathrm{OH}), 1720 \mathrm{~cm}^{-1}(\mathrm{C}=\mathrm{O}), 1600 \mathrm{~cm}^{-1}$ $(\mathrm{C}=\mathrm{C}), 1220 \mathrm{~cm}^{-1}(\mathrm{C}-\mathrm{O})$, and $1070 \mathrm{~cm}^{-1}$ (C-O-C) were observed in the IR spectrum of the pristine graphene oxide, evidencing the presence of carbonyl, carboxyl, alkoxy, epoxy and hydroxyl groups in the sample. Spectra were independent of graphene oxide size. Following the pegylation one could observe both changes in the intensity of the pre-existing absorption bands and the emergence of novel typical absorption bands. Specifically, a.b. at $2870 \mathrm{~cm}^{-1}\left(-\mathrm{CH}_{2}-\right)$ and $1640 \mathrm{~cm}^{-1}(-\mathrm{NH}-\mathrm{CO}-)$ are detected and the a.b. intensity at $1070 \mathrm{~cm}^{-1}$ (C-O-C) is significantly elevated, indicating the presence of PEG in the system as well as for the amide bond formation between amine groups of PEG and GO. One should note the weakening in the a.b. intensity at $1420 \mathrm{~cm}^{-1}(\mathrm{C}-\mathrm{OH})$ that additionally supports the amide bond formation between $-\mathrm{COOH}$ groups of $\mathrm{GO}$ and $-\mathrm{NH}_{2}$ groups of $\mathrm{PEG}-\mathrm{NH}_{2}$.

\subsubsection{Raman Spectroscopy}

Using Raman scattering spectroscopy it was found that GO PEGylation was manifested in an increase in oxygen amount $\left(\mathrm{I}_{\mathrm{D}} / \mathrm{I}_{\mathrm{G}}\right.$ increases from 0.93 to 0.98$)$ and decrease in the proportion of carbon moieties with $\mathrm{sp}^{2}$ bonds. Spectra are independent of graphene oxide size. Values obtained on the relationships of typical band intensities $\left(\mathrm{I}_{\mathrm{D}} / \mathrm{I}_{\mathrm{G}}\right)$ could be interpreted as showing that the processes of carboxylation and subsequent PEGylation did not destroy the aromatic structure of monolayered graphene oxide.

\subsubsection{DLS}

Hydrodynamic diameters and polydispersity indices of GO-PEG are presented in Table 1. Size distribution of SbGO and SnGO is presented in Figure 2C. DLS technique is based on the Einstein-Stokes equation describing the behavior of spherical particles. Being 2D material, GO cannot be accurately characterized by DLS, however, in general, obtained results reflect the size difference between larger and smaller nanoparticles. The zeta potential of GO-PEG is lower than $-30 \mathrm{mV}$, that facilitates their good colloidal stability upon storage in deionized water. 

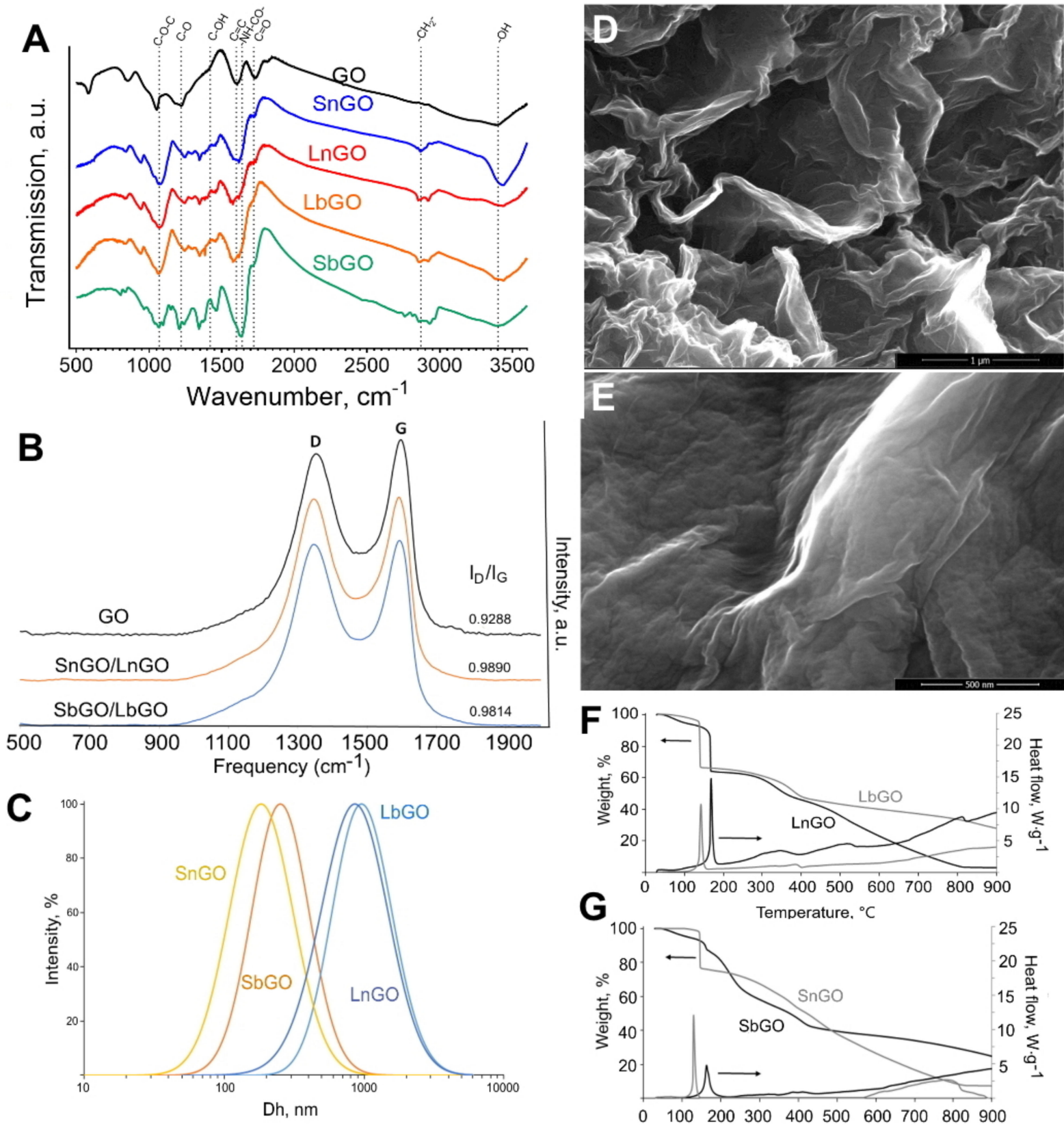

Figure 2. Characterization of GO-PEG. (A) -FTIR spectra; (B)-Raman spectra; (C) - intensityweighted size distribution determined by DLS; (D,E)-SEM images of GO (D) and LbGO (E); $(\mathbf{F}, \mathrm{G})$-TGA/DSC of GO-PEG. Scale bars are $1 \mu \mathrm{m}(\mathbf{D})$ and $500 \mathrm{~nm}(\mathbf{E})$.

Table 1. Properties of GO-PEG.

\begin{tabular}{ccccc}
\hline & SnGO & SbGO & LnGO & LbGO \\
\hline Dh, $\mathrm{nm}^{1}$ & $184 \pm 73$ & $287 \pm 52$ & $891 \pm 18$ & $1376 \pm 48$ \\
\hline PdI & $0.25 \pm 0.02$ & $0.23 \pm 0.02$ & $0.21 \pm 0.02$ & $0.30 \pm 0.01$ \\
\hline Zeta Potential, $\mathrm{mV}$ & $-31.70 \pm 1.70$ & $-34.28 \pm 0.41$ & $-39.98 \pm 1.17$ & $-53.56 \pm 1.23$ \\
\hline PEG Coverage, $\mathrm{wt}^{\circ} \%$ & $17.2 \pm 1.4$ & $20.5 \pm 1.8$ & $19.4 \pm 2.2$ & $20.5 \pm 1.1$ \\
\hline
\end{tabular}

${ }^{1} \mathrm{Dh}$-hydrodynamic diameter, PdI-polydispersity index. 


\subsubsection{TGA}

It is known that GO loses weight in an inert atmosphere at $150-300{ }^{\circ} \mathrm{C}$ due to the thermal decomposition of oxygen-containing groups (Figure S2). This thermal decomposition is accompanied by an exothermic effect. For the studied samples, SbGO and LbGO in a narrow temperature range of $150-170{ }^{\circ} \mathrm{C}$, sharp decreases in mass are observed (Figure $2 \mathrm{~F}, \mathrm{G}$ ), which is probably associated with the transformation of the various oxygen-containing GO groups (carbonyl, carboxyl, alkoxy, epoxy, and hydroxyl groups). For PEGylated samples, one more stage of weight loss is observed in the temperature range $250-450{ }^{\circ} \mathrm{C}$, caused by thermal decomposition of the main chains of the branched PEG polymer. Calculations based on TGA data showed that both SbGO and LbGO contain about $20 \mathrm{wt} \%$ of PEG (Table 1).

The results obtained correspond to those for the samples of GO coated with linear PEG, with the only difference being that the intensities of thermal effects differ and the weight drops in the first temperature range of $150-300{ }^{\circ} \mathrm{C}$ are not so pronounced. The character of the TGA dependences for non-coated graphene oxide is similar to the literature data. However, the data obtained indicate a high oxidation state of the small GO nanoparticles (about $58 \mathrm{wt} \%$ of oxygen). Calculations based on TGA data showed that the SnGo and SnGO samples contain about $17-19 \mathrm{wt} \%$ of PEG (Table 1 ).

\subsubsection{SEM and EDS}

Figure 2 shows typical scanning electron micrographs of the intact GO and LbGO. The rougher surface of PEGylated GO indicates the presence of polymer.

The presence of the PEG polymer on the GO surface was confirmed by elemental analysis using energy-dispersive $X$-ray spectroscopy (EDAX), implemented on a scanning electron microscope. Elemental analysis was performed on the intact GO and SbGO. Examples of mapping and spectra are shown in Figure S3. Intact GO is characterized by the presence of only carbon and oxygen in a ratio of 85:15 at $\%$. In the SbGO sample, in addition to carbon and oxygen, the presence of nitrogen was observed. The atomic ratio of elements in the sample was changed to 74:2:24 (C:O:N). These changes are most likely also associated with the appearance of the branched PEG on the surface of GO nanoparticles.

\subsection{Protein Adsorption by the PEGylated Graphene Oxide}

When encountering cultural fluid containing 10\% human serum GO-PEG nanoparticles accumulate serum proteins on their surface [24]. This so-called protein corona can sufficiently impact the interaction with monocytes. Protein corona of GO-PEG nanoparticles was studied by SPS-PAGE. One hundred $\mu \mathrm{g}$ of GO-PEG was incubated in a culture medium containing $10 \%$ human serum in concentrations of 5 and $25 \mu \mathrm{g} / \mathrm{mL}$. Nanoparticles were collected and washed, then adsorbed proteins were eluted and analyzed by SDS-PAGE. Amount of adsorbed protein was semi-quantitatively measured by the assessment of total protein band intensity (brightness of corresponding lanes on the stained gel). Decrease of brightness indicated higher amount of adsorbed protein.

As expected, small nanoparticles adsorbed more protein than larger ones due to larger specific surface area (Figure 3). Nevertheless, PEGylation can not completely diminish protein adsorption on GO nanoparticles. Branched PEG more efficiently shield nanoparticle surfaces, which can be explained by steric hindrance generated by multiple PEG chains. These data are in agreement with previous studies reporting less intense cell attachment [25] and lower protein absorbance [26] for nanoparticles coated with branched PEG. Unexpectedly, we observed that the adsorption of serum proteins positively correlated with the concentration of nanoparticles. Considering that the concentration of protein in $10 \%$ serum $(6-8 \mathrm{mg} / \mathrm{mL}$ ) is 100-1000-fold higher than that of GO-PEG, one could expect that the surface of nanoparticles will be saturated with protein molecules regardless of nanoparticle concentration. Even if saturation of the GO-PEG surface was not reached at mentioned protein concentration, nanoparticles at $5 \mu \mathrm{L}$ should adsorb more protein because of the higher protein-to-nanoparticle mass ratio. Therefore, an additional experiment was 
performed. We substituted $10 \%$ human serum with $7 \mathrm{mg} / \mathrm{mL}$ BSA. When incubating with BSA, GO-PEG adsorbs the same quantity of protein independent of their concentration (Figure S4). Therefore, it can be inferred that blood serum contains some factors facilitating higher protein adsorption at larger GO-PEG concentrations. Extraordinary interaction of GO with serum proteins has already been demonstrated by Kenry et al. [27]. The authors studied the adsorption of albumin, fibrinogen, and IgG on unmodified GO nanoparticles with various lateral sizes. For BSA a typical relationship was observed: the smaller the nanoparticles the lower adsorption, while contrarily, for fibrinogen adsorption, the pattern was opposite. Moreover, for IgG, no clear dependence of adsorption on lateral size was observed. Besides, at a certain concentration of $\operatorname{IgG}$ and fibrinogen, their adsorption sharply increased by about an order of magnitude in comparison with 2.5 -fold lower concentrations.
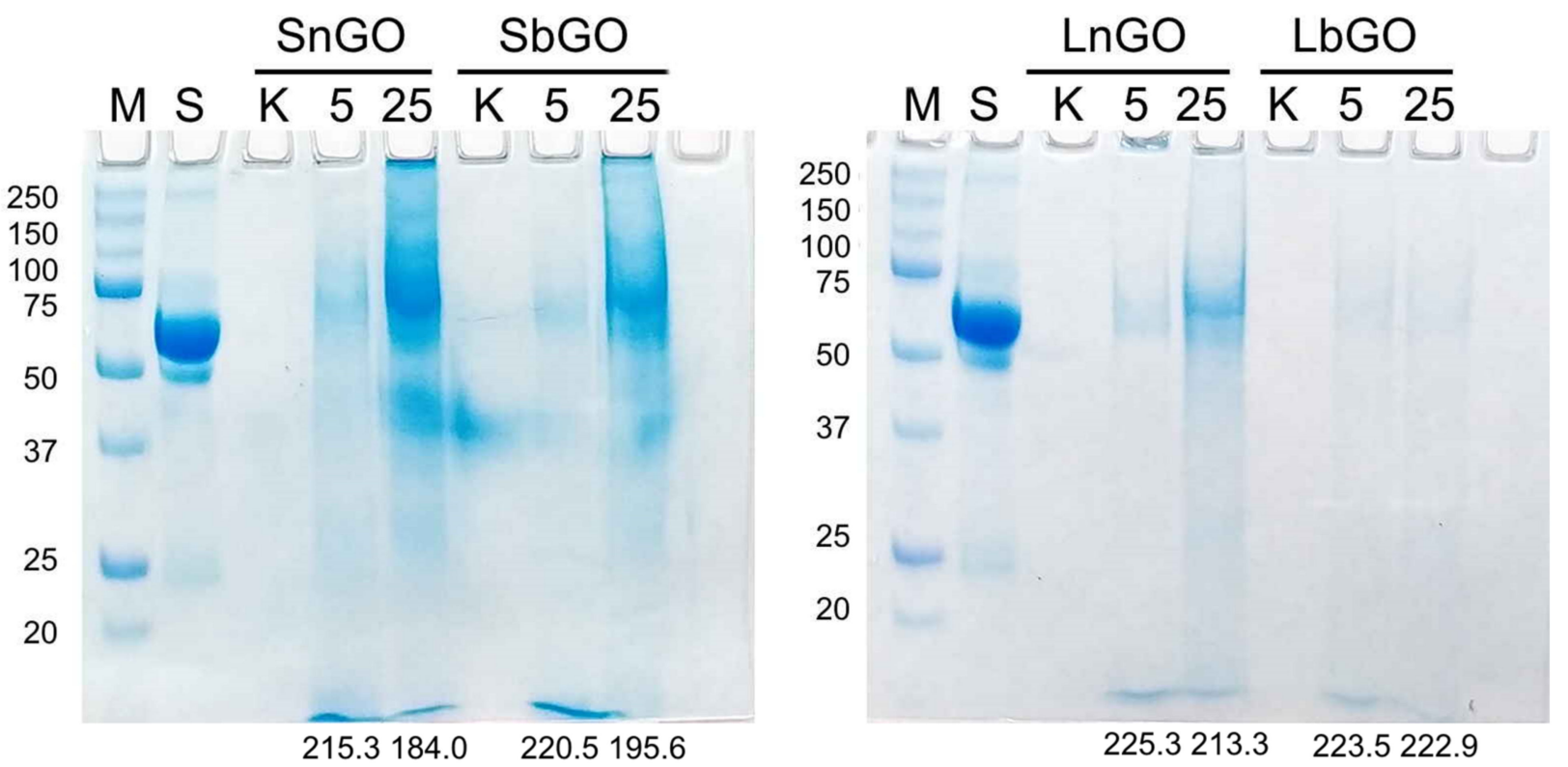

Figure 3. SDS-PAGE of GO-PEG protein corona. $\mathrm{M}$-protein markers, their molecular weights are indicated on the left side. S-1\% human serum. K-GO-PEG $(25 \mu \mathrm{g} / \mathrm{mL})$ incubated in culture medium without $10 \%$ human serum. GO-PEG ( 5 or $25 \mu \mathrm{g} / \mathrm{mL})$ incubated in culture medium with $10 \%$ human serum. Mean gray values, which reflect amount of protein in sample, are presented below corresponding lanes.

A possible explanation of our findings is that higher concentration nanoparticles interact with unidentified serum proteins leading to their multi-layered adsorption. Probably, the formation of complexes, containing several nanoparticles and multiple proteins takes place, because the increase of GO-PEG concentration increases protein adsorption. Phenomena of multi-layered adsorption [28], as well as the dependence of protein adsorption on nanoparticle concentration [29], have been reported for other nanomaterials.

\subsection{Uptake and Cytotoxicity of GO-PEG in Monocytes}

The uptake of nanoparticles is an important characteristic of their interaction with immune cells. Monocytes being professional phagocytic cells are able to ingest particles from surrounding media. We studied whether the coating type and size of GO nanoparticles are responsible for uptake by human blood monocytes. Nanoparticles ( 5 and $25 \mu \mathrm{g} / \mathrm{mL}$ ) were cultured with monocytes in the presence of $10 \%$ human blood serum for $30 \mathrm{~min}$ at $+4{ }^{\circ} \mathrm{C}$ and $+37^{\circ} \mathrm{C}$. Incubation at low temperature represents physical adsorption of GO-PEG whereas both adsorption and uptake of GO-PEG occurs at $+37^{\circ} \mathrm{C}$ allowing discrimination between adsorption and phagocytosis of nanoparticles [30,31]. The percentage of GOPEG-positive monocytes and phagocytosis index (amount of GO-PEG nanoparticles per 
monocyte) were assessed with flow cytometry by measuring the fluorescence of graphene nanoparticles in $\mathrm{Cy} 7$ channel [32].

The amount of SbGO and LbGO per one monocyte was lower in comparison with SnGO and LnGO when nanoparticles $(25 \mu \mathrm{g} / \mathrm{mL})$ were incubated with cells at $+37^{\circ} \mathrm{C}$ (Figure $4 \mathrm{D}, p<0.001)$. It was only at $+4{ }^{\circ} \mathrm{C}$ that a difference for LnGO vs LbGO $(p=0.004)$ but not for SbGO vs SnGO ( $p=0.468)$ was observed (Figure $4 \mathrm{C})$. However, no distinct relationship between the type of PEG (branched or linear) and the number of GO-PEGpositive monocytes was revealed (Figure 4A,B). As expected, the percentage of positive cells was larger at higher GO concentrations. We did not perform a direct comparison of small and large GO-PEG nanoparticles due to their significant size (and, hence, fluorescence) difference.

Branched PEG decreases the number of GO nanoparticles, uptaken by a single cell, however, the number of monocytes that engulfed nanoparticles does not depend on the type of PEG polymer. Our data coincides with findings reported by Vila et al. and Matesanz et al. [22,23]. They showed that branched PEG-modified GO was 2-6-fold less intensively uptaken by various cell lines (osteoblasts and macrophages) than GO coated with linear PEG. Protein adsorption on the nanoparticles (protein corona) can alter the phagocytosis of nanoparticles. Duan et al. reported lower uptake of GO nanoparticles in the presence of $10 \%$ blood serum than in serum-free culture medium [33]. Moreover, it has been shown that certain serum proteins contribute to nanoparticle internalization, in particular that human serum albumin promotes uptake whereas the presence of clusterin in protein corona decreases it [34]. Although we did not study the composition of the GO-PEG protein corona, the GO nanoparticles stabilized with branched PEG showed lower total protein adsorption (Section 3.2.). We suppose that better stealth properties of branched PEG can explain the less intense uptake of GO nanoparticles coated with this type of polymer.

A higher percentage of GO-PEG-positive monocytes at larger GO-PEG concentrations is probably due to the lower number of GO-PEG nanoparticles in cells. Some of the monocytes contain GO-PEG, however the fluorescence of these nanoparticles is not high enough to be detected by the flow cytometer.

The viability of monocytes was assessed by Trypan Blue staining. The percentage of live cells in control was relatively low (median; 1-99 percentiles: 73.0; 63.0-77.0), which is probably due to the isolation procedure. In general, GO-PEG did not alter the cell viability ( $p$ values $>0.999$ vs control for all groups in the Friedman test) however we should note that median viability values were slightly lower when $25 \mu \mathrm{g} / \mathrm{mL}$ of GO-PEG was added (Figure 5). Besides, SnGO at $25 \mu \mathrm{g} / \mathrm{mL}$ decreased the viability of monocytes obtained from 3 of 4 analyzed individuals to $47-51 \%$. Similarly, in previous studies with both cell lines and cells isolated from mice (peritoneal macrophages, splenocytes, and bone marrow-derived dendritic cells) GO-PEG had no [6,35] or negligible (3-10\% decrease) $[22,23,36,37]$ impact on cell viability. In agreement with the earlier report [23], we did not observe any difference between the cytotoxicity of GO modified with linear and branched PEG. 
A

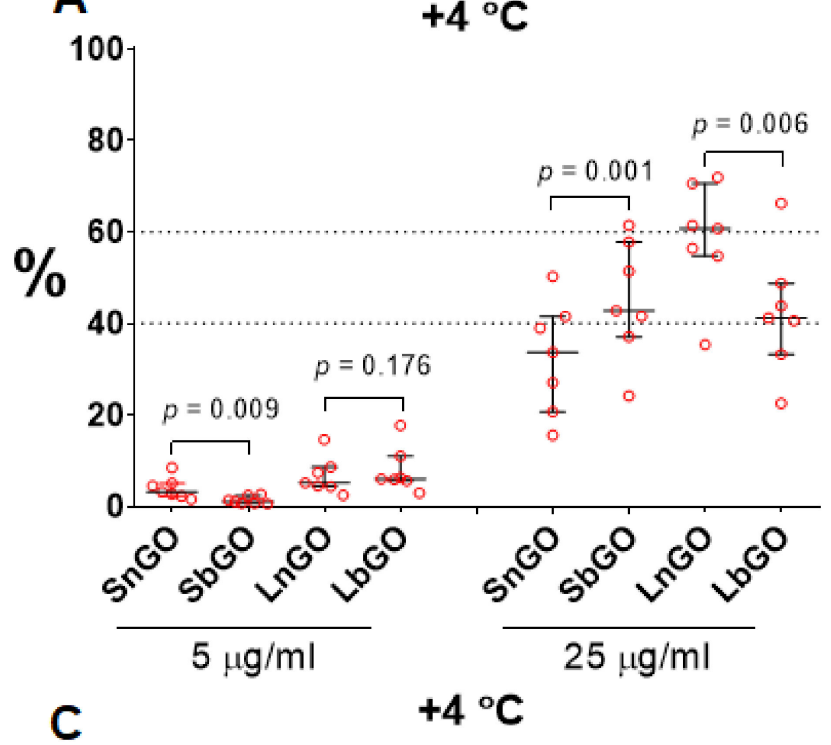

B

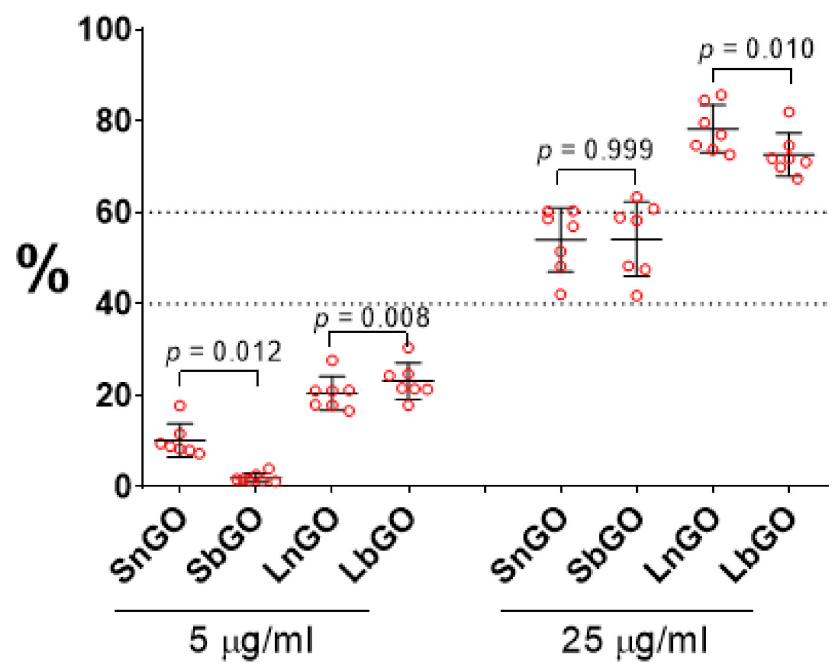

D

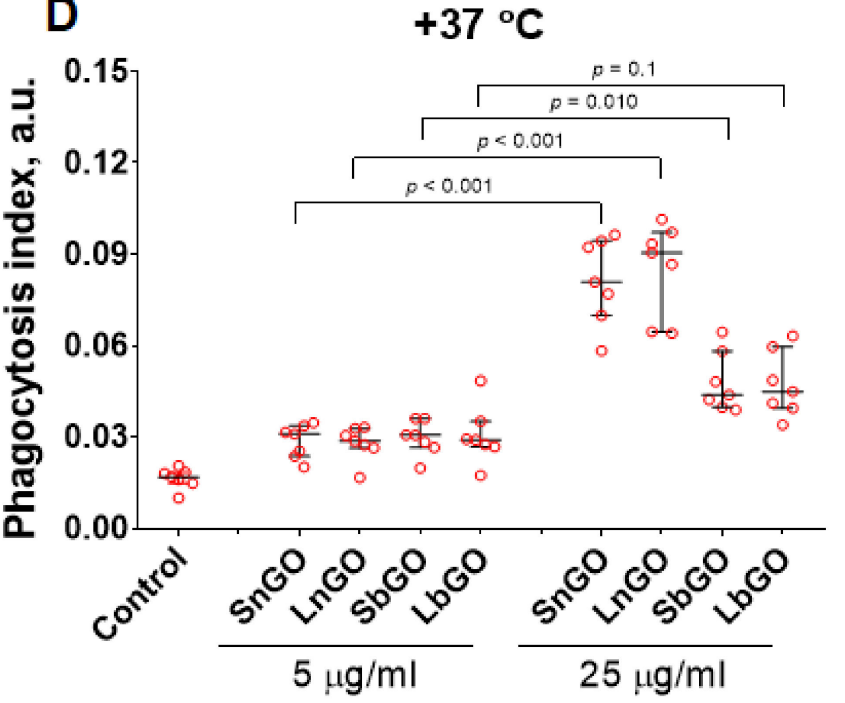

Figure 4. Percentage of GO-PEG positive cells in monocyte gate $(\mathbf{A}, \mathbf{B})$ and phagocytosis index $(\mathbf{C}, \mathbf{D})$. Incubation of monocytes with GO-PEG was carried out at +4 and at $+37^{\circ} \mathrm{C}$. Dotted lines are drawn for easier visual comparison of results. $n=7$, median and interquartile range are reported. Data were analyzed by repeated measurements one-way ANOVA with Sidak post-hoc correction for multiple comparisons. 


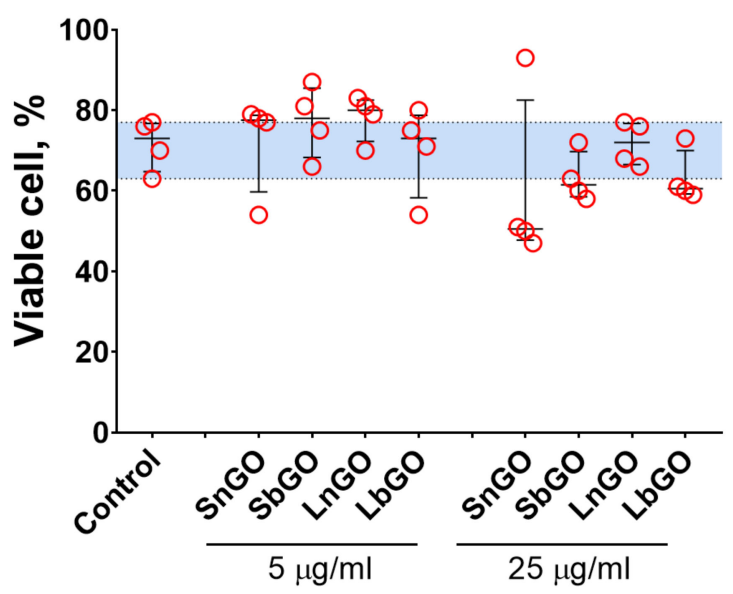

Figure 5. Viability of monocytes cultivated with GO-PEG for $24 \mathrm{~h}$. $\mathrm{n}=4$, median and interquartile range are reported. Data were analyzed by Friedman test with Dunn's post-hoc correction for multiple comparisons. Blue area represents 1-99 percentile range of control.

\subsection{Phagocytosis}

Monocytes realize defense functions against pathogens via numerous mechanisms including phagocytosis and intracellular killing. Previous works have reported that graphenebased and other nanomaterials can both enhance [38,39] and suppress $[40,41]$ the ability of phagocytic cells to engulf pathogens.

We studied whether interaction with graphene oxide nanoparticles influences the phagocytosis capacity of monocytes. Monocytes were preincubated with graphene oxide for $30 \mathrm{~min}$ or $24 \mathrm{~h}$ at $+37^{\circ} \mathrm{C}$, then FITC-labelled E. coli were added to graphene-treated monocytes and kept for $30 \mathrm{~min}$ at $+37^{\circ} \mathrm{C}$. Percentage of monocytes that engulfed bacteria, as well as the number of bacteria per monocyte (phagocytosis index) were measured.

Pre-incubation of monocytes with GO-PEG for $30 \mathrm{~min}$ did not affect the E. coli uptake. Prolonged graphene pre-treatment increased the number of FITC-positive monocytes in the control sample, perhaps due to the restoration of phagocytosis ability that was impaired by the cell isolation process (Figure 6, control samples).

Monocytes treated with $25 \mu \mathrm{g} / \mathrm{mL}$ of GO-PEG for $24 \mathrm{~h}$ less intensively engulfed bacteria: percentage of $E$. coli-positive monocytes declined by $10-15 \%$ in comparison with control cells (monocytes that did not interact with GO-PEG). The most prominent decrease was observed in monocytes contacted with $25 \mu \mathrm{g} / \mathrm{mL}$ of SbGO (15\% decrease; $p=0.010)$ and LbGO (14\% decrease; $p=0.002)$ (Figure 6).

Phagocytosis index was also lower in monocytes incubated with $25 \mu \mathrm{g} / \mathrm{mL}$ of GO-PEG for $24 \mathrm{~h}$, however statistical comparison with the control group is underpowered due to small sample size and large between-individuals variability.

The decline of phagocytosis percentage cannot be explained solely by reaching the limit of phagocytosis capacity by monocytes after GO-PEG pre-treatment, because several studies have reported enhanced phagocytic activity after interaction with nanomaterials [38,39]. The possible mechanism of inhibition of phagocytosis is an interaction of GO-PEG with F-actin [22,40]. This interaction affects the cytoskeleton and, hence, might change the phagocytic activity of monocytes. 
Phagocytosis
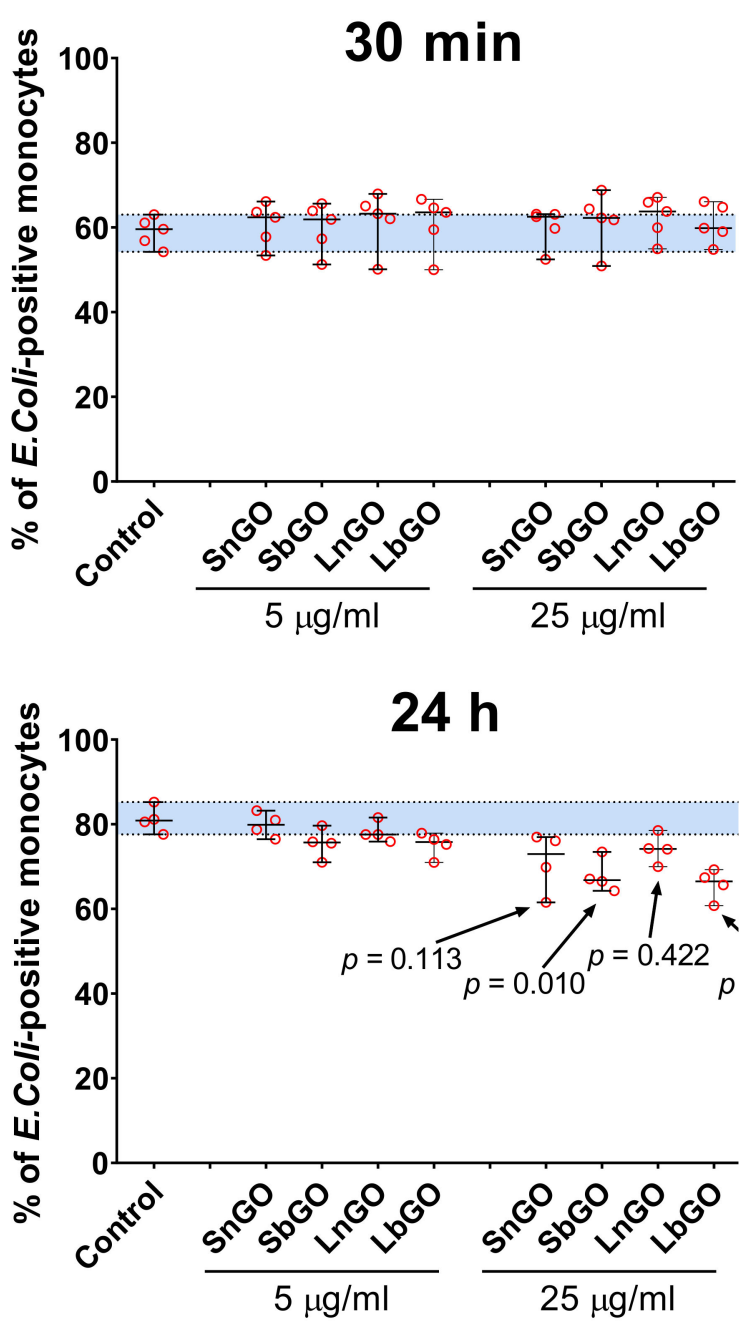

Phagocytosis index $30 \mathrm{~min}$

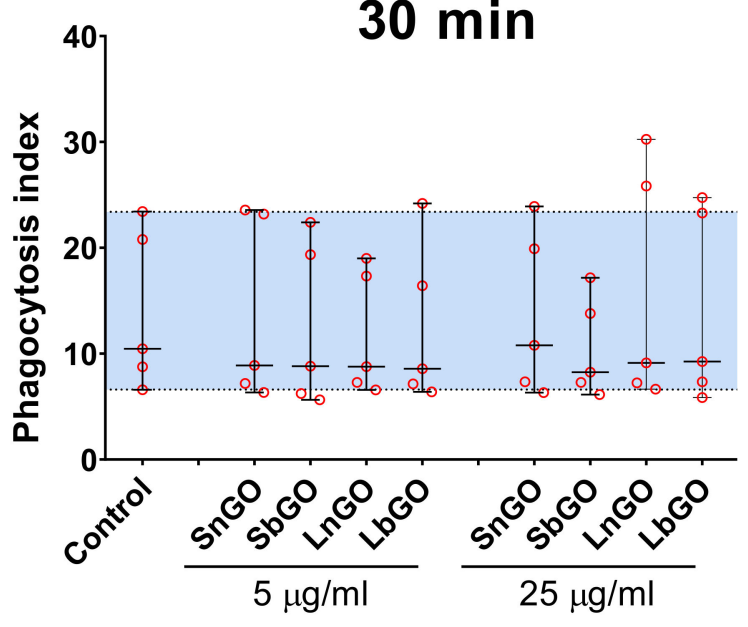

$24 \mathrm{~h}$

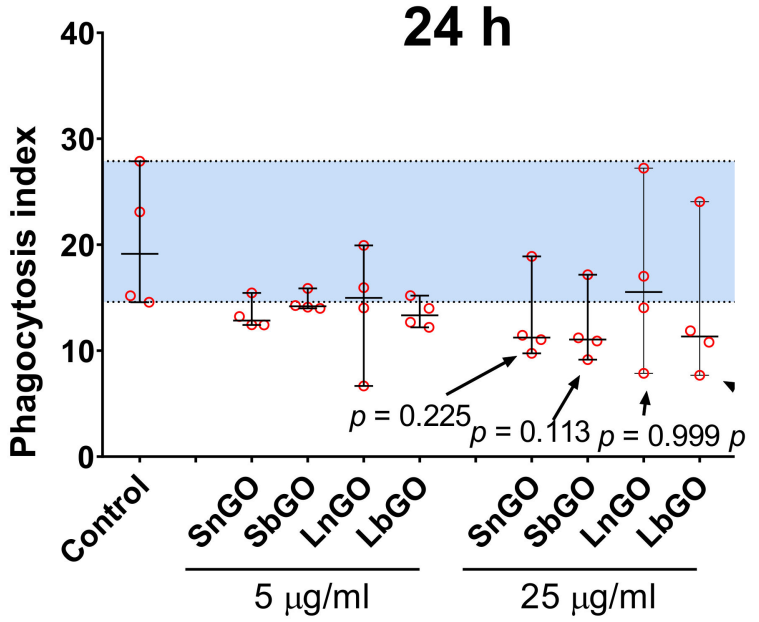

Figure 6. Phagocytosis of E. coli by monocytes and phagocytosis index. Monocytes were successively incubated with GO-PEG for $30 \mathrm{~min}$ or $24 \mathrm{~h}$ and with FITC-labelled E. coli for $30 \mathrm{~min}$. The $\mathrm{n}=5$ (30 $\mathrm{min})$ or $n=4(24 \mathrm{~h})$, median and interquartile range are reported. Data were analyzed by Friedman test with Dunn's post-hoc correction for multiple comparisons. Blue area represents 1-99 percentile range of control. $p$ values indicate comparison to control sample.

\section{5. $R O S$}

Monocytes produce reactive oxygen species to destroy pathogens $[42,43]$. In addition, ROS can increase the production of pro-inflammatory cytokines by monocytes / macrophages [44,45], as well as inducing apoptosis of $\mathrm{T}$ cells and monocytes themselves $[46,47]$. The regulation of ROS production by monocytes depends on the balance between the activation of NADPH oxidase (a multicomponent enzyme system) and the cellular levels of various antioxidant molecules [48].

Disruption of this regulation may lead to excessive oxidative stress, which in turn may serve as one of the links in the pathogenesis of diseases such as Alzheimer's disease, chronic obstructive pulmonary disease, atherosclerosis, cancer, and others [49].

The Graphene family of nanomaterials change ROS production in immune cells [50]. Moreover, stimulation of ROS production is considered as one of the key mechanisms of graphene cytotoxicity [51]. ROS formation was measured with fluorescent and chemiluminescent tracers: luminol, lucigenin, and DCFH. Monocytes were mixed with GO-PEG and tracer, then luminescence was measured for $60 \mathrm{~min}$. Opsonized zymosan was added 
to some samples in order to study the effects of GO-PEG on ROS production by activated monocytes. GO-PEG decreased luminol- and lucigenin-mediated luminescence (Figure 7). The observed effect was concentration-dependent. In the non-activated cells, GO-PEG decreased luminol-mediated chemiluminescence but did not affect lucigenin- and DCFHmediated chemiluminescence. Size and PEG structure did not influence the results.

Despite many papers reporting that GO induces ROS formation in immune cells [50], GO can also hinder ROS production when acting as a ROS scavenger due to its multiple $\mathrm{sp}^{2}$ carbon atoms [5]. Besides, GO is an efficient luminescent quencher [52] and is, therefore, able to interfere with ROS detection techniques [35]. This fact makes the interpretation of results quite complex because the observed decrease of ROS production at higher GO concentration can be explained simply by its quenching ability, but not by an effect on cell physiology. We studied the influence of GO-PEG on $\mathrm{H}_{2} \mathrm{O}_{2}$-induced luminescence of lucigenin and luminol in cell-free conditions and revealed that GO-PEG at $25 \mu \mathrm{g} / \mathrm{mL}$ quenched lucigenin luminescence, but enhanced luminescence of luminol (Figure S5). Therefore, even if GO-PEG stimulated the production of ROS, the lucigenin-dependent luminescence induced by ROS production could not surpass the quenching effect of nanoparticles. Taking into account the enhancing effect of GO-PEG on luminol-dependent chemiluminescence, we suggest that GO-PEG can realize either inactivation of ROS produced by monocytes (antioxidant effect) or direct suppression of ROS production. Lucigenin mostly detects superoxide ions, whereas DCFH and luminol have less specificity and are able to detect various ROS species [53]. GO was shown to inactivate hydroxyl radicals [4,54] and superoxide radicals, but not hydrogen peroxide [4]. Therefore, we suggest that the inactivation of hydroxyl and superoxide radicals by GO-PEG can explain the decrease of chemiluminescence.

There are many reports on stimulation of ROS production by pristine GO, whereas PEGylated GO shows ambiguous effects. Six-armed and linear PEG-modified GO increased ROS production in osteoblasts and macrophages (RAW-264.7) [22]. Reduced GO-PEG stimulated production of intracellular ROS in mice bone marrow-derived dendritic cells and bone marrow mesenchymal stem cells [55,56]. At the same time, two research groups have demonstrated that GO-PEG did not stimulate the production of intracellular ROS in human breast cancer cells (MCF-7) [35,57]. GO-PEG had almost no effect on the ROS production by human neutrophils [58]. Direct comparison of our results with these data is challenging because the authors used various concentrations of GO-PEG, different incubation times, and ROS measurement modes.

\subsection{Cytokines}

Cytokines are small proteins secreted by both immune and non-immune cells which orchestrate homing, activation, and proliferation of immune cells as well as immune response polarization. Knowledge about the ability of GO-PEG to alter cytokine production by monocytes is essential for the development of GO-based adjuvants and therapeutics. We cultivated monocytes in the presence of GO-PEG and measured the concentration of three cytokines-TNF $\alpha$, IL-6, IL-10. It is known that TNF $\alpha$ and IL-6 realize the pro-inflammatory regulatory activity of cytokines, while IL-10 has anti-inflammatory activity. 

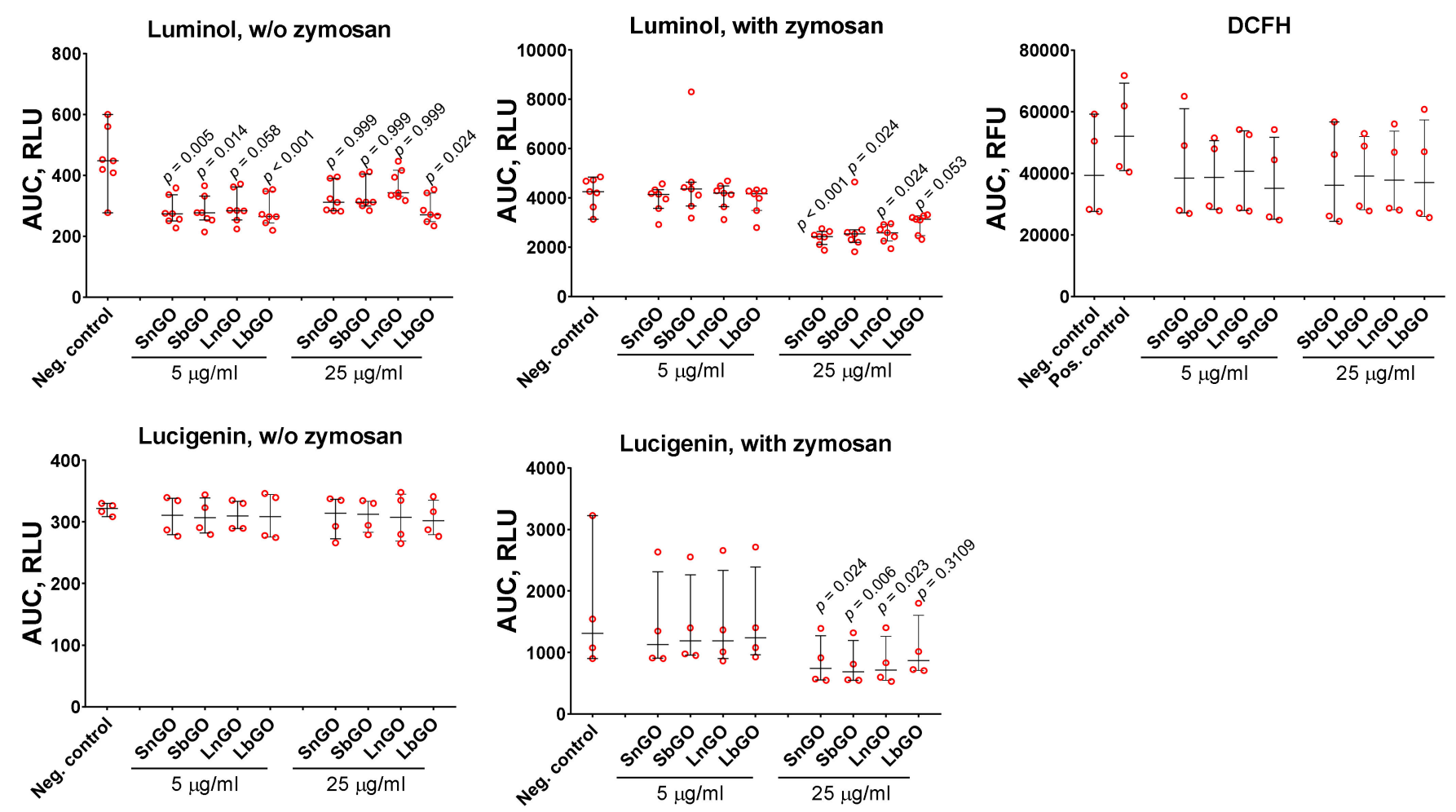

Figure 7. ROS formation by monocytes measured by luminescent tracers: luminol, lucigenin, and DCFH. In some samples zymosan was used as an activator. Negative control-cultural fluid without GO-PEG. Positive control-zymosan (DCFH experiment). $\mathrm{n}=4$ for DCFH and lucigenin experiments, $\mathrm{n}=7$ for luminol experiment, median and interquartile range are reported. Data were analyzed by Friedman test with Dunn's post-hoc correction for multiple comparisons. AUC-area under luminescence/fluorescence vs. time curve. RLU-relative luminescent units. RFU-relative fluorescent units. $p$ values indicate comparison with control sample.

Before experiments, we measured the concentration of endotoxin (LPS) in GO-PEG preparations [59]. Obtained values were compared with data on the effect of endotoxin on monocytes obtained by Schwarz et al. [60] taking into account the dilution factor. The authors of the mentioned work reported that endotoxin at a concentration of $0.02 \mathrm{EU} / \mathrm{mL}$ did not change the production of IL-1beta, IL-6, IL-8, and TNF $\alpha$ as well as expression levels of CD40, CD80, CD83, and CD86 by human monocytes. The concentration of endotoxin measured by the LAL test in all GO-PEG preparations was higher than $0.02 \mathrm{EU} / \mathrm{mL}$ (Table S1), therefore polymyxin B was added in cell culture medium to quench the effects of endotoxin. The amount of polymyxin B added was capable of inactivating endotoxin in concentration as high as $100 \mathrm{ng} / \mathrm{mL}$ being, therefore, a large excess in relation to measured endotoxin concentration. Excess of polymyxin B was used because LAL-test can underestimate endotoxin concentration due to its ability to adsorb on nanoparticles [61].

SnGO at $25 \mu \mathrm{L}$ and LbGO at 5 and $25 \mu \mathrm{L}$ increased the production of IL-10. For TNF $\alpha$ and IL-6 median cytokine concentrations were higher in comparison with control, but $\mathrm{p}$ values exceeded 0.1. Monocytes from four donors were tested in these experiments. The between-donor difference in both basal and GO-induced cytokine production was very high and reached an order of magnitude. Cells isolated from donors 1 and 2 had lower basal levels of cytokine secretion and were much less sensitive to GO-PEG compared with that of donors 3 and 4 (Figure 8). We suppose that there is some probability of SnGO and LbGO influence of TNF $\alpha$ and IL-6 production, however further studies are necessary. In general, there was no clear relation between the size of GO nanoparticles or the type of PEG, and the change of cytokine production. Despite polymyxin B being added, there is still a chance 
that endotoxin adsorbed on graphene surface and corona proteins avoided inactivation and interacted with LPS receptors after GO-PEG were uptaken by monocytes. This suggestion is based on results obtained by Jurgens et al. [62] who showed that human serum albumin binds multiple LPS molecules and decreases the binding of LPS to polymyxin B. Moreover, adsorption on nanoparticles can by itself significantly enhance the pro-inflammatory effect of LPS [63]. Orecchioni et al. reported that GO caused a non-cell-specific production of all analyzed cytokines in a variety of cell populations, whereas the effect of LPS was more specific [64].
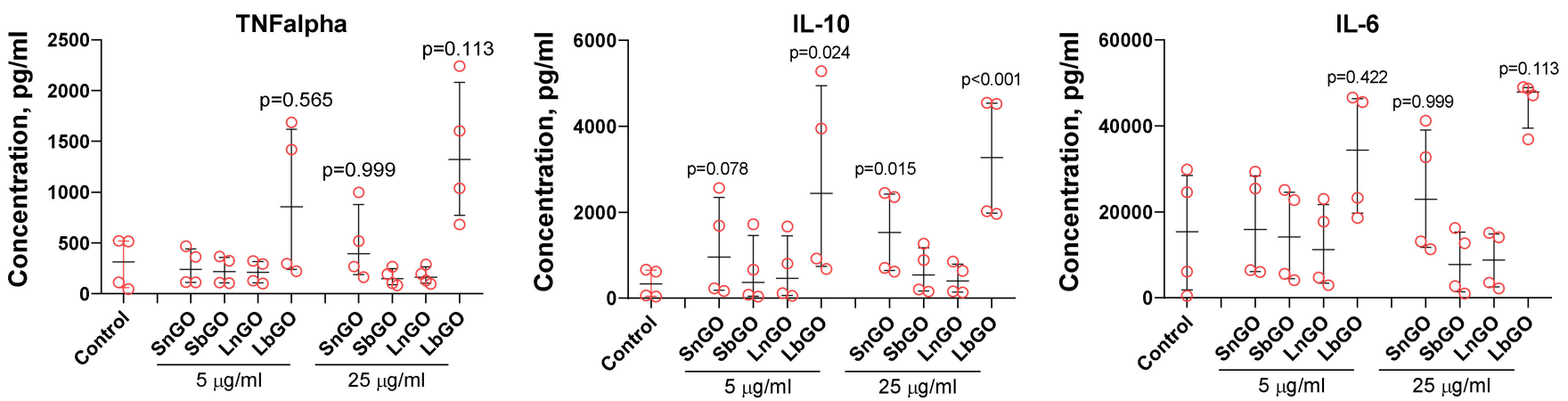

Figure 8. Cytokine production by monocytes cultivated with GO-PEG. Control—cultural fluid without GO-PEG. Polymyxin B $(10 \mu \mathrm{M})$ was added in all samples. $n=4$, median and interquartile range are reported. Data were analyzed by Friedman test with Dunn's post-hoc correction for multiple comparisons. $p$ values indicate comparison with control sample.

Results of recent studies dedicated to the effects of GO-PEG on cytokine production by various immune cells are contradictory. Cytokine production depends on cell type [22] and grafting density of PEG molecules on GO [65]. We did not assess the number of PEG chains per one GO nanoparticle, but the mass fraction of PEG was almost the same in all GO-PEG. Some authors demonstrated enhanced secretion of TNF $\alpha$ by RAW-264.7 macrophages [36], peritoneal macrophages [65], and mice bone marrow-derived dendritic cells [56]. Interestingly, the production of $\mathrm{TNF} \alpha$ by peritoneal macrophages decreased after $24 \mathrm{~h}$ of incubation but increased after $48 \mathrm{~h}$ [37]. In the same papers, the increase of TNF $\alpha$ production did not correlate with changes in the production of IL-10, IL-6, and other cytokines $[36,56,65]$. Importantly, most cited studies lack information about endotoxin content in tested nanoparticle preparations which significantly complicates the comparative analysis of their results.

\section{Conclusions}

Summarizing the obtained results, we can conclude that PEGylated graphene oxide influences the functions of monocytes such as cytokine production, phagocytosis, and ROS formation. The ability of GO-PEG to reduce phagocytosis of bacterial cells and ROS formation indicates that GO-PEG can potentially inhibit the elimination of pathogens by the immune cells. Graphene oxide is considered a promising component of antimicrobial therapeutics owing to its toxicity towards bacterial cells [66]. Inhibition of antibacterial properties of monocytes can, therefore, reduce the efficiency of GO towards pathogen elimination. An increase of cytokine production by the monocytes upon interaction with GO-PEG can change the polarization of immune response leading to inadequate and, hence, inefficient reaction of the immune cells on the pathogen, which is important when graphene is utilized as adjuvant in vaccines [7].

Endotoxin contamination of GO-PEG significantly complicates the interpretation and comparison of the results on immunotoxicity of GO-based nanomaterials. In this work, we used GO-PEG contaminated with endotoxin, so we had to add polymyxin B to the culture medium. Preparation of apyrogenic GO-PEG is a challenging task, which requires GO 
synthesized in endotoxin-free conditions. Such products are of limited commercial availability, whereas their in-house synthesis can be conducted only in a specialized laboratory. Therefore, optimized methods for the preparation of apyrogenic GO of desirable size are of great importance as well as methods for post-synthesis depyrogenation, which do not alter the structural integrity of GO-PEG.

Supplementary Materials: The following are available online at https: / / www.mdpi.com/article / 10.3390/nano12010126/s1. Figure S1: Measurement of the mean brightness of the SDS-PAGE lane using Image J. Pink frame indicates selected area. Mean grey value is displayed in the Results table, Figure S2: TGA curve of GO, Figure S3: Mapping and EDS spectra of GO with lateral size of 100-200 nm (A,B) and SbGO (C,D), Figure S4: SDS-PAGE of GO-PEG incubated with BSA. M-protein markers, their molecular weights are indicated on the left side. B-1\% BSA. K-GO-PEG $(25 \mu \mathrm{g} / \mathrm{mL})$ incubated in culture medium without BSA. 5 and 25-GO-PEG ( 5 or $25 \mu \mathrm{g} / \mathrm{mL}$ ) incubated in culture medium with $7 \mathrm{mg} / \mathrm{mL}$ BSA. Mean gray values, which reflect amount of protein in sample, are presented below corresponding lanes, Figure S5: Luminescence of luminol $(20 \mu \mathrm{M})$ and lucigenin $(5 \mu \mathrm{M})$ induced by $\mathrm{H} 2 \mathrm{O} 2(0.625 \%$ and $2.5 \%$, respectively) in the presence of GO-PEG. Controlsample without GO-PEG. $\mathrm{N}=3$, median and interquartile range are reported. Data were analyzed by repeated measurements one-way ANOVA with Holm-Sidak post-hoc correction for multiple comparisons. p values indicate comparison to control sample, Table S1: Concentration of endotoxin in GO-PEG, EU/mL.

Author Contributions: Conceptualization, S.Z. and M.R.; investigation, P.K., M.B., V.T., A.N., S.U., K.S. and I.M.; writing-original draft preparation, P.K. and V.T.; supervision, S.Z. and M.R. All authors have read and agreed to the published version of the manuscript.

Funding: This work was supported by Russian Scientific Foundation grant no. 19-15-00244.

Institutional Review Board Statement: This research was performed according to World Medical Association's Declaration of Helsinki and Council of Europe Protocol to the Convention on Human Rights and Biomedicine and approved by the Ethics Committee of the Institute of Ecology and Genetics of Microorganisms, Ural Branch of the Russian Academy of Sciences (IRB00010009).

Informed Consent Statement: Written informed consent was obtained from all the participants.

Data Availability Statement: The datasets used and/or analyzed during the current study are available from the corresponding author on reasonable request.

Conflicts of Interest: The authors declare no conflict of interest.

\section{References}

1. Anichini, C.; Samorì, P. Graphene-based hybrid functional materials. Small 2021, 17, 2100514. [CrossRef] [PubMed]

2. Smith, A.T.; LaChance, A.M.; Zeng, S.; Liu, B.; Sun, L. Synthesis, properties, and applications of graphene oxide/reduced graphene oxide and their nanocomposites. Nano Mater. Sci. 2019, 1, 31-47. [CrossRef]

3. Teunissen, A.J.P.; Burnett, M.E.; Prévot, G.; Klein, E.D.; Bivona, D.; Mulder, W.J.M. Embracing nanomaterials' interactions with the innate immune system. Wiley Interdiscip. Rev. Nanomed. Nanobiotechnol. 2021, 13, 1719. [CrossRef] [PubMed]

4. Qiu, Y.; Wang, Z.; Owens, A.C.; Kulaots, I.; Chen, Y.; Kane, A.B.; Hurt, R.H. Antioxidant chemistry of graphene-based materials and its role in oxidation protection technology. Nanoscale 2014, 6, 11744-11755. [CrossRef]

5. Han, J.; Kim, Y.S.; Lim, M.-Y.; Kim, H.Y.; Kong, S.; Kang, M.; Kim, B.-S. Dual Roles of graphene oxide to attenuate inflammation and elicit timely polarization of macrophage phenotypes for cardiac repair. ACS Nano. 2018, 12, 1959-1977. [CrossRef]

6. Xu, L.; Xiang, J.; Liu, Y.; Xu, J.; Luo, Y.; Feng, L.; Liu, Z.; Peng, R. Functionalized graphene oxide serves as a novel vaccine nano-adjuvant for robust stimulation of cellular immunity. Nanoscale 2016, 8, 3785-3795. [CrossRef]

7. Cao, W.; He, L.; Cao, W.; Huang, X.; Jia, K.; Dai, J. Recent progress of graphene oxide as a potential vaccine carrier and adjuvant. Acta Biomater. 2020, 112, 14-28. [CrossRef]

8. Yin, Y.; Li, X.; Ma, H.; Zhang, J.; Yu, D.; Zhao, R.; Yu, S.; Nie, G.; Wang, H. In situ transforming RNA nanovaccines from polyethylenimine functionalized graphene oxide hydrogel for durable cancer immunotherapy. Nano Lett. 2021, 21, $2224-2231$. [CrossRef]

9. Dudek, I.; Skoda, M.; Jarosz, A.; Szukiewicz, D. The molecular influence of graphene and graphene oxide on the immune system under in vitro and in vivo conditions. Arch. Immunol. Ther. Exp. Engl. Transl. 2016, 64, 195-215. [CrossRef]

10. Karlmark, K.R.; Tacke, F.; Dunay, I.R. Monocytes in health and disease-Minireview. Eur. J. Microbiol. Immunol. 2012,2 , 97-102. [CrossRef] 
11. Dale, D.C.; Boxer, L.; Liles, W.C. The phagocytes: Neutrophils and monocytes. Blood 2008, 112, 935-945. [CrossRef]

12. Kashimura, T.F. A scanning electron microscopy study of human spleen; relationship between the microcirculation and function. Scanning Microsc. 1987, 1, 841-851.

13. Geske, F.J.; Monks, J.; Lehman, L.; Fadok, V.A. The role of the macrophage in apoptosis: Hunter-gatherer and regulator. Int. J. Hematol. 2002, 76, 16-26. [CrossRef]

14. Lameijer, M.A.; Tang, J.; Nahrendorf, M.; Beelen, R.H.; Mulder, W.J. Monocytes and macrophages as nanomedicinal targets for improved diagnosis and treatment of disease. Expert. Rev. Mol. Diagn. 2013, 13, 567-580. [CrossRef]

15. Orecchioni, M.; Jasim, D.A.; Pescatori, M.; Manetti, R.; Fozza, C.; Sgarrella, F.; Bedognetti, D.; Bianco, A.; Kostarelos, K.; Delogu, L.G. Molecular and genomic impact of large and small lateral dimension graphene oxide sheets on human immune cells from healthy donors. Adv. Healthc. Mater. 2016, 5, 276-287. [CrossRef]

16. Feng, R.; Yu, F.; Xu, J.; Hu, X. Knowledge gaps in immune response and immunotherapy involving nanomaterials: Databases and artificial intelligence for material design. Biomaterials 2021, 266, 120469. [CrossRef]

17. Ghosh, S.; Chatterjee, K. Poly (Ethylene glycol) functionalized graphene oxide in tissue engineering: A review on recent advances. Int. J. Nanomed. 2020, 15, 5991-6006. [CrossRef]

18. Abdel-Mageed, H.M.; AbuelEzz, N.Z.; Radwan, R.A.; Mohamed, S.A. Nanoparticles in nanomedicine: A comprehensive updated review on current status, challenges and emerging opportunities. J. Microencapsul. 2021, 38, 414-436. [CrossRef]

19. Xu, Z.; Wang, S.; Li, Y.; Wang, M.; Shi, P.; Huang, X. Covalent Functionalization of Graphene Oxide with Biocompatible Poly(ethylene glycol) for Delivery of Paclitaxel. ACS Appl. Mater. Interfaces 2014, 6, 17268-17276. [CrossRef]

20. Mukherjee, S.P.; Lozano, N.; Kucki, M.; Del Rio-Castillo, A.E.; Newman, L.; Vazquez, E.; Kostarelos, K.; Wick, P.; Fadeel, B. Detection of endotoxin contamination of graphene based materials using the TNF- $\alpha$ expression test and guidelines for endotoxin-free graphene oxide production. PLoS ONE 2016, 11, e0166816. [CrossRef]

21. Achawi, S.; Pourchez, J.; Feneon, B.; Forest, V. Graphene-based materials in vitro toxicity and their structure-activity relationships: A systematic literature review. Chem. Res. Toxicol. 2021, 34, 2003-2018. [CrossRef]

22. Matesanz, M.-C.; Vila, M.; Feito, M.-J.; Linares, J.; Gonçalves, G.; Vallet-Regi, M.; Marques, P.A.A.P.; Portolés, M.-T. The effects of graphene oxide nanosheets localized on F-actin filaments on cell-cycle alterations. Biomaterials 2013, 34, 1562-1569. [CrossRef]

23. Vila, M.; Portolés, M.T.; Marques, P.A.; Feito, M.J.; Matesanz, M.C.; Ramírez-Santillán, C.; Gonçalves, G.; Cruz, S.M.; Nieto, A.; Vallet-Regi, M. Cell uptake survey of pegylated nanographene oxide. Nanotechnology 2012, 23, 465103. [CrossRef]

24. Franqui, L.S.; De Farias, M.A.; Portugal, R.V.; Costa, C.A.R.; Domingues, R.R.; Souza Filho, A.G.; Coluci, V.R.; Leme, A.F.P.; Martinez, D.S.T. Interaction of graphene oxide with cell culture medium: Evaluating the fetal bovine serum protein corona formation towards in vitro nanotoxicity assessment and nanobiointeractions. Mater. Sci. Eng. C Mater. Biol. Appl. 2019, 100, 363-377. [CrossRef]

25. Mastrotto, F.; Brazzale, C.; Bellato, F.; De Martin, S.; Grange, G.; Mahmoudzadeh, M.; Magarkar, A.; Bunker, A.; Salmaso, S.; Caliceti, P. In vitro and in vivo behavior of liposomes decorated with PEGs with different chemical features. Mol. Pharm. 2020, 17, 472-487. [CrossRef]

26. Tong, L.; He, W.; Zhang, Y.; Zheng, W.; Cheng, J.-X. Visualizing systemic clearance and cellular level biodistribution of gold nanorods by intrinsic two-photon luminescence. Langmuir 2009, 25, 12454-12459. [CrossRef]

27. Kenry, K.; Loh, K.P.; Lim, C.T. Molecular interactions of graphene oxide with human blood plasma proteins. Nanoscale 2016, 8 , 9425-9441. [CrossRef]

28. Sotnikov, D.V.; Berlina, A.N.; Ivanov, V.S.; Zherdev, A.V.; Dzantiev, B.B. Adsorption of proteins on gold nanoparticles: One or more layers? Colloids Surf. B. Biointerfaces 2019, 173, 557-563. [CrossRef]

29. Rahimi, M.; Ng, E.-P.; Bakhtiari, K.; Vinciguerra, M.; Ahmad, H.A.; Awala, H.; Mintova, S.; Daghighi, M.; Rostami, F.B.; Vries, M.; et al. Zeolite nanoparticles for selective sorption of plasma proteins. Sci. Rep. 2015, 5, 17259. [CrossRef]

30. Leijh, P.C.J.; Barselaar, M.T.; Furth, R. Kinetics of phagocytosis and intracellular killing of staphytococcus aureus and escherichia coli by human monocytes. Scand. J. Immunol. 1981, 13, 159-174. [CrossRef]

31. Santos, J.L.; Montes, M.J.; Gutiérrez, F.; Ruiz, C. Evaluation of phagocytic capacity with a modified flow cytometry technique. Immunol. Lett. 1995, 45, 1-4. [CrossRef]

32. Singh, S.K.; Singh, M.K.; Nayak, M.K.; Kumari, S.; Grácio, J.J.; Dash, D. Characterization of graphene oxide by flow cytometry and assessment of its cellular toxicity. J. Biomed. Nanotech. 2011, 7, 30-31. [CrossRef] [PubMed]

33. Duan, G.; Kang, S.; Tian, X.; Garate, J.A.; Zhao, L.; Ge, C.; Zhou, R. Protein corona mitigates the cytotoxicity of graphene oxide by reducing its physical interaction with cell membrane. Nanoscale 2015, 7, 15214-15224. [CrossRef] [PubMed]

34. Schöttler, S.; Becker, G.; Winzen, S.; Steinbach, T.; Mohr, K.; Landfester, K.; Mailänder, V.; Wurm, F.R. Protein adsorption is required for stealth effect of poly(ethylene glycol)- and poly(phosphoester)-coated nanocarriers. Nat. Nanotechnol. 2016, 11, 372-377. [CrossRef]

35. Peruzynska, M.; Cendrowski, K.; Barylak, M.; Tkacz, M.; Piotrowska, K.; Kurzawski, M.; Mijowska, E.; Drozdzik, M. Comparative in vitro study of single and four layer graphene oxide nanoflakes-Cytotoxicity and cellular uptake. Toxicol. Vitro 2017, 41, 205-213. [CrossRef]

36. Feito, M.J.; Vila, M.; Matesanz, M.C.; Linares, J.; Gonçalves, G.; Marques, P.A.A.P.; Vallet-Regí, M.; Rojo, J.M.; Portolés, M.T. In vitro evaluation of graphene oxide nanosheets on immune function. J. Colloid Interface Sci. 2014, 432, 221-228. [CrossRef] 
37. Feito, M.J.; Diez-Orejas, R.; Cicuéndez, M.; Casarrubios, L.; Rojo, J.M.; Portolés, M.T. Characterization of M1 and M2 polarization phenotypes in peritoneal macrophages after treatment with graphene oxide nanosheets. Colloids Surf. B Biointerfaces 2019, 176, 96-105. [CrossRef]

38. Diez-Orejas, R.; Feito, M.J.; Cicuéndez, M.; Casarrubios, L.; Rojo, J.M.; Portolés, M.T. Graphene oxide nanosheets increase Candida albicans killing by pro-inflammatory and reparative peritoneal macrophages. Colloids Surf. B Biointerfaces 2018, 171, 250-259. [CrossRef]

39. Al Rugaie, O.; Jabir, M.; Kadhim, R.; Karsh, E.; Sulaiman, G.M.; Mohammed, S.; Khan, R.A.; Mohammed, H.A. Gold nanoparticles and graphene oxide flakes synergistic partaking in cytosolic bactericidal augmentation: Role of ROS and NOX2 activity. Microorganisms 2021, 9, 101. [CrossRef]

40. Zhou, T.; Zhang, B.; Wei, P.; Du, Y.; Zhou, H.; Yu, M.; Yan, L.; Zhang, W.; Nie, G.; Chen, C.; et al. Energy metabolism analysis reveals the mechanism of inhibition of breast cancer cell metastasis by PEG-modified graphene oxide nanosheets. Biomaterials 2014, 35, 9833-9843. [CrossRef]

41. Wagner, A.J.; Bleckmann, C.A.; Murdock, R.C.; Schrand, A.M.; Schlager, J.J.; Hussain, S.M. Cellular interaction of different forms of aluminum nanoparticles in rat alveolar macrophages. J. Phys. Chem. 2007, 111, 7353-7359. [CrossRef]

42. Babior, B.M. Oxidants from phagocytes: Agents of defense and destruction. Blood 1984, 64, 959-966. [CrossRef]

43. Elbim, C.; Hakim, J.; Gougerot-Pocidalo, M.-A. Heterogeneity in Lewis-X and sialyl-Lewis-X antigen expression on monocytes in whole blood: Relation to stimulus-induced oxidative burst. Am. J. Pathol. 1998, 152, 1081-1090.

44. Chaudhri, G.; Clark, I.A. Reactive oxygen species facilitate the in vitro and in vivo lipopolysaccharide-induced release of tumor necrosis factor. J. Immunol. 1989, 143, 1290-1294.

45. Gougerot-Pocidalo, M.-A.; Roche, Y.; Fay, M.; Perianin, A.; Bailly, S. Oxidative injury amplifies interleukin-1-like activity produced by human monocytes. Int. J. Immunopharmacol. 1989, 11, 961-969. [CrossRef]

46. Um, H.-D.; Orenstein, J.M.; Wahl, S.M. Fas mediates apoptosis in human monocytes by a reactive oxygen intermediate dependent pathway. J. Immunol. 1996, 156, 3469-3477.

47. Laochumroonvorapong, P.; Paul, S.; Elkon, K.B.; Kaplan, G. $\mathrm{H}_{2} \mathrm{O}_{2}$ induces monocyte apoptosis and reduces viability of Mycobacterium avium-M. intracellulare within cultured human monocyte. Infect. Immun. 1996, 64, 452-459. [CrossRef]

48. Seres, T.; Ravichandran, V.; Moriguchi, T.; Rokutan, K.; Thomas, J.A.; Johnston, J.R.B. Protein S-thiolation and dethiolation during the respiratory burst in human monocytes: A reversible post-translational modification with potential for buffering the effects of oxidant stress. J. Immunol. 1996, 156, 1973-1980.

49. Forman, H.J.; Zhang, H. Targeting oxidative stress in disease: Promise and limitations of antioxidant therapy. Nat. Rev. Drug Discov. 2021, 20, 689-709. [CrossRef]

50. Yunus, M.A.; Ramli, M.M.; Osman, N.H.; Mohamed, R. Stimulation of innate and adaptive immune cells with graphene oxide and reduced graphene oxide affect cancer progression. Arch. Immunol. Ther. Exp. Engl. Transl. 2021, 69, 20. [CrossRef]

51. Tabish, T.A.; Zhang, S.; Winyard, P.G. Developing the next generation of graphene-based platforms for cancer therapeutics: The potential role of reactive oxygen species. Redox Biol. 2018, 15, 34-40. [CrossRef]

52. $\mathrm{Wu}, \mathrm{X} . ;$ Xing, Y.; Zeng, K.; Huber, K.; Zhao, J.X. Study of fluorescence quenching ability of graphene oxide with a layer of rigid and tunable silica spacer. Langmuir 2018, 34, 603-611. [CrossRef]

53. Freitas, M.; Lima, J.L.F.C.; Fernandes, E. Optical probes for detection and quantification of neutrophils' oxidative burst. A review. Anal. Chim. Acta 2009, 649, 8-23. [CrossRef]

54. Marković, Z.M.; Jovanović, S.P.; Mašković, P.Z.; Mojsin, M.M.; Stevanović, M.J.; Danko, M.; Mičušík, M.; Jovanović, D.J.; Kleinová, A.; Špitalský, Z.; et al. Graphene oxide size and structure pro-oxidant and antioxidant activity and photoinduced cytotoxicity relation on three cancer cell lines. J. Photochem. Photobiol. B 2019, 200, 111647. [CrossRef]

55. Syama, S.; Aby, C.P.; Maekawa, T.; Sakthikumar, D.; Mohanan, P.V. Nano-bio compatibility of PEGylated reduced graphene oxide on mesenchymal stem cells. 2D Mater. 2017, 4, 25066. [CrossRef]

56. Moon, J.J.; Xu, C.; Hong, H.; Lee, Y.; Park, K.S.; Sun, M.; Wang, T.; Aikins, M.E.; Xu, Y. Efficient lymph node-targeted delivery of personalized cancer vaccines with reactive oxygen species-inducing reduced graphene oxide nanosheets. ACS Nano 2020, 14, 13268-13278. [CrossRef]

57. Jang, S.-C.; Kang, S.-M.; Lee, J.Y.; Oh, S.Y.; Vilian, A.T.E.; Lee, I.; Han, Y.-K.; Park, J.H.; Cho, W.-S.; Roh, C.; et al. Nano-graphene oxide composite for in vivo imaging. Int. J. Nanomed. 2018, 13, 221-234. [CrossRef]

58. Lu, Y.-J.; Wang, Y.-H.; Sahu, R.S.; Chen, J.-P.; Dash, B.S.; Chung, P.-J.; Yang, H.-W.; Chuang, E.-Y.; Hwang, T.-L. Mechanism of nanoformulated graphene oxide-mediated human neutrophil activation. ACS Appl. Mater. Interfaces 2020, 12, 40141-40152. [CrossRef]

59. Li, Y.; Fujita, M.; Boraschi, D. Endotoxin Contamination in Nanomaterials Leads to the Misinterpretation of Immunosafety Results Front. Immunol. 2017, 8, 472. [CrossRef]

60. Schwarz, H.; Schmittner, M.; Duschl, A.; Horejs-Hoeck, J. Residual endotoxin contaminations in recombinant proteins are sufficient to activate human CD1c+ dendritic cells. PLoS ONE 2014, 9, e113840. [CrossRef]

61. Lahiani, M.H.; Gokulan, K.; Williams, K.; Khodakovskaya, M.V.; Khare, S. Graphene and carbon nanotubes activate different cell surface receptors on macrophages before and after deactivation of endotoxins. J. Appl. Toxicol. 2017, 37, 1305-1316. [CrossRef] [PubMed] 
62. Jürgens, G.; Müller, M.; Garidel, P.; Koch, M.H.J.; Nakakubo, H.; Blume, A.; Brandenburg, K. Investigation into the interaction of recombinant human serum albumin with Re-lipopolysaccharide and lipid A. J. Endotoxin Res. 2002, 8, 115-126. [CrossRef] [PubMed]

63. Bianchi, M.G.; Allegri, M.; Chiu, M.; Costa, A.L.; Blosi, M.; Ortelli, S.; Bussolati, O.; Bergamaschi, E. Lipopolysaccharide adsorbed to the bio-corona of $\mathrm{TiO} 2$ nanoparticles powerfully activates selected pro-inflammatory transduction pathways. Front. Immunol. 2017, 8, 866. [CrossRef] [PubMed]

64. Orecchioni, M.; Bedognetti, D.; Newman, L.; Fuoco, C.; Spada, F.; Hendrickx, W.; Marincola, F.M.; Sgarrella, F.; Rodrigues, A.F.; Ménard-Moyon, C.; et al. Single-cell mass cytometry and transcriptome profiling reveal the impact of graphene on human immune cells. Nat. Commun. 2017, 8, 1109. [CrossRef]

65. Luo, N.; Weber, J.K.; Wang, S.; Luan, B.; Yue, H.; Xi, X.; Du, J.; Yang, Z.; Wei, W.; Zhou, R.; et al. PEGylated graphene oxide elicits strong immunological responses despite surface passivation. Nat. Commun. 2017, 8, 14537. [CrossRef]

66. Xia, M.Y.; Xie, Y.; Yu, C.H.; Chen, G.Y.; Li, Y.H.; Zhang, T.; Peng, Q. Graphene-based nanomaterials: The promising active agents for antibiotics-independent antibacterial applications. J. Control. Release 2019, 307, 16-31. [CrossRef] 